highly variable. This surely also applies to bone accretion. In a remote complex of villages in western Transvaal, where all families are fairly poor and subsist on a similar frugal, near vegetarian diet, we found considerable differences between children, aged 10-12 years, not only in cortical indices of metacarpal but also in haemoglobin, serum cholesterol, and albumin concentrations and transit time. Such variability could not be explained by differences in diet.

It would seem that the determinants of bone mass are not understood fully and that bone mass is susceptible to little modification, whether in reaching maximal accretion or during subsequent loss with age.

A R P WALKER B F WALKER

South African Institute for Medical Reserch,

Johannesburg 2000

South Africa

1 Riggs BL, Melton LJ. Involutional osteoporosis. N Engl f Med 1986;314:1676-86.

2 National Institutes of Health. Osteoporosis: consensus conference. FAMA 1984;252:799-802.

3 United States Department of Health Education and Welfare. Dietary intake source data, United States, 1971-74. Maryland, United States: United States Department of Health Edycation and Welfare, 1979:2-145. (DHEW publication No (PHS) 79-1221.)

4 Reid IR, Mackie M, Ibbertson HK. Bone mineral content in Polynesian and white New Zealand women. $\mathrm{Br} M e d \mathcal{F}$ 1986;292:1547-8.

5 Stott S, Gray DH. The incidence of femoral neck fractures in New Zealand. NZ Med J 1980;91:6-9.

6 Solomon L. Bone density in ageing caucasian and African populations. Lancet 1979;ii:1326-30.

7 Walker ARP, Richardson BD, Walker BF. The influence of numerous pregnancies and lactations on bone dimensions in South.African Bantu and caucasian mothers. Clin Sci 1972;42: 189-96.

8 Dent CE, Engelbrecht HE, Godfrey RC. Osteoporosis of lumbar vertebrae and calcification of abdominal aorta in women living in Durban. Br Med f 1968;iv:76-9.

\section{When a woman asks for a caesarean section}

SIR,-Dr Marion Hall (24 January, p 201) suggests that women should be dissuaded from having a caesarean section if they request one without a clear medical indication. An elective caesarean section, even of a normal pregnancy at term, however, may avert an unexpected disaster and, as elective section is safer than emergency section, may also be safer for the mother. ${ }^{12} \mathrm{~A}$ woman may consider even a 1/1000 hypothetical reduction in fetal mortality to be worth pursuing, although her obstetrician may regard the benefit as unproved. The statement that a reduction in the fetal risk of breech delivery by caesarean section is inconsistent with the results of Collea's study ${ }^{3}$ is absurd; that trial was much too small to show even large differences in fetal death or damage.

Those who would refuse caesarean section at the mother's request should consider their response to the opposite circumstance, when a woman requests a trial of labour with a high risk to the fetus. Dr Hall was a defence witness in the Wendy. Savage inquiry, which debated how far an obstetrician is justified in allowing a patient to risk her baby's life by attempting vaginal delivery. We would agree with Drs Hall and Savage that the principle of autonomy means that an informed mother is entitled to refuse intervention without undue pressure from the obstetrician. She should also, however, be free to risk her own life or inconvenience herself for small potential fetal benefit. We suspect that $\mathrm{Dr}$ Hall wishes to promote a particular mode of childbirth under the guise of promoting women's choice.

In the past we have attempted to obtain estimates of the relative values women attach to fetal and maternal life but have found women to be unable and unwilling to contemplate such choices. We are now conducting surveys to define at what fetal risk women would request caesarean section if there was no additional maternal mortality. Subjects are asked to consider the other possible adverse effects of the operation. Most women claim that they would request caesarean section at remarkably low fetal risks, with a median response of $1 / 4000$. In contrast, a small group of women who had undergone or requested a home delivery had a median response of $1 / 100$. We hope that such surveys may show how different desires for obstetric intervention reflect either differen perceptions of the actual risks and benefits of a procedure or different values of the outcomes Where values differ there will always be argument as to whose values should be used, but at least a little light may have been shed where there is presently much heat.

General Infirmary,

J G THORNTON

St James's University Hospital

R J LILFORD

Leed

1 Feldman GB, Freiman JA. Prophylactic cesarean section at term? N Engl f Med 1985;312:1264-7.

2 Bingham $P$, Lilford $R$. The management of the mature selected breech presentation: a decision analysis. Obstet Gynecol (in press).

3 Collea JV, Chein C, Quilligan EJ. The randomised management of term frank breech presentation: a study of 208 cases. $A m$ Obstet Gynecol 1980;137:235-42.

\section{Psychiatric disorder and gynaecological symptoms in middle aged women}

SIR,-The study by Dr Dennis Gath and colleague (24 January, $p$ 213) raises a number of problems of interpretation.

It is surprising that their rating of gynaecological symptoms does,not include measures of severity or subjective distress and particularly unfortunate that they did not use the operational definitions and standard ratings that have been developed for the premenstrual syndrome, ${ }^{12}$ dysmenorrhoea, and the climacteric syndrome. ${ }^{4}$ The measures of premenstrual syndrome used by $\mathrm{Dr}$ Gath and coworkers are weakened further by the retrospective collection of data and the lack of information on symptoms at other stages in the subjects menstrual cycles, as are the measures of dysmenorrhoea by the lack of distinction between the primary and secondary forms of the disorder. These problems not only render valid comparisons with other recent studies impossible but also increase the likelihood that the gynaecological ratings are contaminated by the very psychiatric symptoms to which an apparent relation is shown.

The reported association between vasomotor symptoms and psychiatric "caseness" is especially problematic. Dr Gath and colleagues found no direct relation between vasomotor symptoms and menopausal state (although McKinlay's widely accepted menopausal staging was not used ${ }^{4}$ ) and none between any psychiatric symptoms and age, but psychiatric and vasomotor symptoms were found to be related to menopausal state in, and only in, the 45-49 age range. No multivariate statistical techniques were used to resolve these inconsistencies. Dr Gath and coworkers suggest that life events may be a link between psychiatric and gynaecological symptoms. The justification for this is obscure as, although they replicate the well established association between life events and psychiatric illness, "life events were not significantly associated with any type of gynaecological symptom recorded in the survey."

Our recent review of studies examining psy- chiatric symptoms in the context of gynaecological disorders not only showed the conflicting nature of the evidence for a psychosocial basis for these disorders but also suggested a biological cause for many common gynaecological disorders and for the psychiatric symptoms often associated with them. ${ }^{6}$ The study by Dr Gath and others will be read widely, and, in view of the methodological flaws in its design and data analysis, it is important that its implied conclusion, that many gynaecological symptoms are psychiatric in origin, should not be accepted uncritically.

GARY BELL

Cornelius Katona

Academic Department of Psychiatry,

Middlesex Hospital Medical School,

London W1N 8AA

1 Steiner $M$, Haskett RF, Carroll BJ. Premenstrual tension syndrome: the development of research diagnostic criteria and drome: the development of research diagnostic criteria

2 Sanders D. Hormones and behaviour during the menstrual cycle. Edinburgh: University of Edinburgh, 1981. (PhD Thesis.)

3 Andersch B, Milsom I. An epidemiologic study of young women with dysmenorrhoea. Am $\mathcal{J}$ Obstet Gynecol 1982;144:655-60.

4 McKinlay S, Jefferys $M$. An investigation of age at menopause f Biosoc Sci 1972;4:161-73.

5 Greene JG, Cooke DJ. Life stress and symptoms at the climacteric. Br F Psychiatry 1980;136:486-91.

6 Bell G, Katona C. Disorders associated with menstruation, pregnancy and the postpartum period. In: Prasad A, ed. Biological understanding and therapy of neuroses. Florida: CRC Bress (in press).
Prelogical undersan.

AUTHORS' REPLY,-Contrary to the assertion by Drs $G$ Bell and $C$ Katona, we used subjective and objective measures of severity for all gynaecological symptoms, examples of which were given in tables III and IV of our paper. We also included measures of distress as stated in the paper, of which some were subjective and others concerned with interference with life. Nearly all of the ratings in the study were operationally defined.

We are familiar with all the standard measures recommended by Drs Bell and Katona, but they would not have been useful for our purposes. For example, of the two scales recommended for rating the climacteric syndrome, the first has a psychological factor (mixture of anxiety and depressive symptoms) and a somatic factor, which includes rheumatic pains, peripheral numbness, and black spots before the eyes. As stated in our paper, we preferred to avoid such a non-specific definition and stick to vasomotor symptoms. The second scale merely divides women according to whether or not they have menstruated in the past three months, in the past three to 12 months, or more than 12 months ago. We preferred a similar scale, with a six rather than three month interval.

With regard to the criticisms of our measures of the premenstrual syndrome, we believe different methods suit different purposes. In an epidemiological survey of the kind we described it was feasible only to ask each woman whether in the preceding six months she had experienced specified symptoms solely or more severely in the five days before the onset of menstruation. Such questioning tells us what the woman believes about her symptoms, which was the focus of our enquiry. For other purposes concurrent ratings are required in the form of daily diary ratings over about 12 weeks. We have used such a procedure in another study and found interview measures of premenstrual symptoms but not diary measures of premenstrual peaking of symptoms to be significantly associated with psychiatric state.

Concerning the distinction between primary and secondary forms of dysmenorrhoea, in our community survey we focused on feasible questions about the frequency and severity of menstrual pain during the preceding six months. Attempts to date the onset of dysmenorrhoea in the past would have been pointless because of the possibility of distorted recall. Information about pelvic disease would have been valuable, but this may be obtained only in a study based on clinical examination and investigation.

With regard to the "contamination" of our gynaecological ratings by psychiatric symptoms, in the paper we suggested that an apparent link between psychiatric state and the psychological symptoms of the pre- 